\title{
Defining airflow obstruction
}

To the Editor:

The authors of the article published recently in the European Respiratory Journal on the prevalence and correlates of airflow obstruction in $>317000$ never-smoking Chinese subjects concluded that they found inconsistent associations with exposures to household air pollution and went on to outline what future work needed to be done [1]. In the first instance, they should present table 5 having reanalysed their data using just lower limits of normal (LLNs) to define airflow obstruction. Their figure 3 shows the expected underdiagnosis of airflow obstruction in those aged $<55$ years when using the Global Initiative for Chronic Obstructive Lung (GOLD) criterion of forced expiratory volume in 1 s/forced vital capacity $<0.7$ when compared with the LLN. Probably just over half their subjects are below this age. All further analysis in table 5 of their paper [1] used the flawed [2] GOLD definition. The authors state that because the baseline variables in table 4 (apart from age) had similar associations with airflow obstruction by the two definitions (GOLD and LLN), they only went on to use the GOLD definition. In doing so, their analysis only included 10325 subjects (table 3) who had airflow obstruction by the GOLD definition and the additional 8166 who had airflow obstruction by LLN were classed in their analysis as "no obstruction", and so will confound and defeat any analysis looking for associations between markers of indoor pollution and airflow obstruction. They must rerun their analysis using all 18491 subjects with airflow obstruction by LLN. A presentation at the 2014 European Respiratory Society International Congress, NeupANE et al. [3] found that in female Nepalese cooks, they could not detect a significant association between indoor pollution and airflow obstruction when using the GOLD criteria but they did find a significant association when using LLN criteria.

Other workers have found that when looking for key associations with chronic obstructive pulmonary disease, the significance of the putative association (e.g. with telomere shortening [4]) was substantially increased when the correct LLN definition was used instead of the GOLD definition. Before considering additional studies, the authors should first present table 5 adhering to the LLN criterion, which will increase the power of their study to detect any associations.

@ERSpublications

Using the GOLD rather than LLN to define obstruction may reduce studies' power to detect associations with exposures http://ow.ly/DgZW9

Martin R. Miller

Institute of Occupational and Environmental Medicine, University of Birmingham, Birmingham, UK.

Correspondence: Martin R. Miller, Institute of Occupational and Environmental Medicine, University of Birmingham, Birmingham B15 2TT, UK. E-mail: m.r.miller@bham.ac.uk

Received: Aug 282014 | Accepted: Oct 092014

Conflict of interest: None declared.

\section{References}

1 Smith M, Li L, Augustyn M, et al. Prevalence and correlates of airflow obstruction in 317 000 never-smokers in China. Eur Respir J 2014; 44: 66-77.

2 Quanjer PH, Miller MR, Stocks J, et al. The need to change the method for defining mild airway obstruction. Prim Care Respir J 2010; 19: 288-291.

3 Neupane M, Rehfuess EA, Froeschl G, et al. Household air pollution and airway obstruction in female cooks of rural Nepal: a comparative study of biogas and firewood users. Eur Respir J 2014; 44: Suppl. 58, 3211.

4 Albrecht E, Sillanpää E, Karrasch S, et al. Telomere length in circulating leukocytes is associated with lung function and disease. Eur Respir J 2014; 43: 983-992. 